\title{
CONSIDERACIONES SOBRE DIOS PARA NUESTRO TIEMPO
}

\author{
Considerations about God for our Time \\ José Carlos CaAmaño ${ }^{1}$
}

\section{Resumen}

Este artículo nos presenta en cinco tópicos algunas consideraciones en el estilo de desafíos para hablar de Dios en nuestro contexto actual. La tensión entre fidelidad al mensaje y escucha de las nuevas exigencias del tiempo es una preocupación que atraviesa todo el artículo. El objetivo es advertir acerca de algunos aspectos a los que debemos prestar atención en nuestros lenguajes y métodos de análisis. Los lenguajes y los métodos condicionan las conclusiones, por lo que el camino que recorramos, aunque creativo, puede arribar a puertos ya estandarizados. En este sentido, aunque nuestro equipaje sea clásico, si nos animamos a recorrer nuevos espacios, es probable que advirtamos desafíos inéditos. A su vez, dialoga con algunos momentos destacados del magisterio de Francisco, quien expresa su preocupación por una fosilización ideológica, funcional y clerical del mensaje evangélico. Los cinco puntos se inician con el desafío por confesar la fidelidad de un Dios, aparentemente, esquivo y distante. Continúa con el planteo de la verdad desde las dos tentaciones que han atravesado la cuestión: entenderla como sólida, inmóvil y acabada, o asumirla como un dinamismo dionisiaco e inaferrable y etéreo. El tercer momento es el ingreso en la cuestión de la verdad de Dios como aquel que existe en comunión y se revela a la humanidad como quien persevera en su presencia. Este misterio de presencia y comunión abre a la tratativa de la cuestión de la persona y la diferencia en Dios como fundamento también del diálogo y la tolerancia. Finalmente, y como olvido de estas dinámicas, se advierte sobre la siempre actual lógica de la idolatría.

\section{Palabras clave:}

Fidelidad; Ser; Relación; Absoluto; Persona; Comunión; Presencia; Diferencia; Idolatría; Humanidad.

1 Doctor en Teología por la Pontificia Universidad Católica Argentina. Profesor ordinario titular en la Facultad de Teología y coordinador del Grupo de Investigación de Cultura Popular en la misma Universidad. Director de la Revista Teología. Miembro del Grupo Iberoamericano de Teología, con Sede en el Boston College, EE. UU. Es también miembro del Grupo Ecclesia In América, con Sede en Universidad de Notre Dame, EE. UU - Pontificia Universidad Católica de Río de Janeiro, Brasil, y del Grupo de Trabajo CLACSO sobre "El cuidado de la casa común" con el tema "Dios". Correo electrónico: josecarcaa@uca.edu.ar 


\section{Abstract}

The article addresses, in five points, some considerations regarding some of the challenges faced when talking about God in our time. The tension between the fidelity of the message and paying attention to the new demands of our time is a concern that is present across it. The aim of the article is to warn against some aspects we must consider in our language and approaches. The latter determine the conclusions, and because of that we might reach standardized answers, despite of how creative our way is. Thus, though our approaches might be traditional, if we dare explore new spaces, it is likely that we might find novel challenges. Likewise, the article considers some remarkable moments of the magisterium of Pope Francis, who has expressed some concerns regarding an ideological, functional, and clerical paralysis of the Gospel. The article begins with the difficulty of admitting the fidelity of a God, who appears to be elusive and distant. Then, it considers truth from the standpoint of two risks: understanding it as solid, unmovable, and complete; or seeing it as dynamic, ungraspable, and ethereal. Third, it addresses the issue of the truth of God, as a being that exists in communion with humanity and that persists in its presence. This mystery of presence and communion leads to the issue of the persona and difference in God as foundation both for dialogue and tolerance. Finally, it warns against the always latent logic of idolatry.

\section{Keywords:}

Fidelity; Being; Relationship; Absolute; Person; Communion; Presence; Difference; Idolatry; Humanity.

\section{El desafío por confesar la fidelidad de Dios}

El Dios del buen samaritano (Lc 10, 29-37) y el padre del hijo pródigo (Lc 15, 11-32) constituyen dos rostros que expresan las perspectivas desde las que sustentaré mi propuesta. No escribiré sobre esos versículos, pero son el marco desde el que considero que es fundamental volver siempre a pensar la particularidad del Dios de Jesucristo. De ese Dios que nos abraza cuando nosotros y nuestros hermanos nos han juzgado y que nos levanta cuando todas las exigencias humanas indicaban como justo y santo dejarnos caídos al costado del camino. Se trata de recorrer el lenguaje de la misericordia como misteriosa paradoja que permite hablar de Él. Es la tensión que experimentamos ante su ternura, que se vuelve aparentemente esquiva y olvidadiza de la menesterosidad humana.

Al culminar su incisivo libro Jesús y Yahvé: los nombres divinos de Dios, Harold Bloom (2006) afirmaba:

No confío en la Alianza, ni en Freud, ni en la reduccionista oposición de Sam Harris entre el "futuro de la razón” y el terror religioso. La necesidad (o ansia) de trascendencia puede ser que sea algo totalmente opuesto a la sabiduría, pero sin ella nos convertimos en simples mecanismos de entropía. Yavé, presente y ausente, tiene más que ver con el fin de la confianza que con el fin de la fe. Y yo me pregunto ¿establecerá otra alianza con nosotros que pueda y quiera cumplir? (p. 242) 
Deseo tensar la pregunta que hace Bloom (2006) y, de algún modo, pensar en el resquebrajo que la historia posee y desde el cual podemos atisbar algo de lo divino. Esa hendidura, esa herida desde la que nada se veía y ahora desde la cruz de Cristo se vislumbra la vida. Lugar de plenitud que es, a la vez, espacio

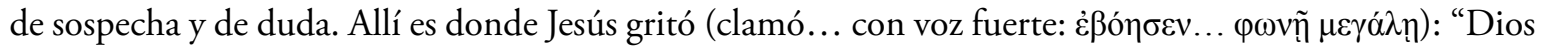

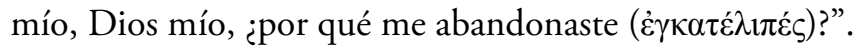

En este sentido, es sumamente sabia la enseñanza de Lutero cuando ante los optimismos racionalistas de las teologías de su tiempo recuerda que conocemos a Dios desde esa herida, desde la cruz. Dios no quiere ser comprendido en lo que es invisible, sino en lo que es visible y manifiesto (visibilia). De lo contrario, la teología es nada; porque Dios ha hablado, podemos hablar de Dios. Debido a que Dios se reveló a sí mismo, sabemos dónde hay que mirar. En su interpretación del Magnificat (1521), Lutero escribiría que Dios mira "solamente en las profundidades, no a las alturas", y "cuanto más lejos uno está por debajo de él, mejor Él se ve". Al respecto, debemos recordar aquella carta del 9 de noviembre de 1545, de Bartolomé de las Casas al rey Felipe de España, en la cual acentuaba que las "herejías" de los luteranos no eran tan malas, comparadas con lo que se hizo contra los indígenas, "ya que las herejías luteranas no han dejado de lado nuestra fe inmaculada y firme, ni han dejado de orar a nuestro Dios, el Cristo crucificado" (Dreher, 2017, p. 65).

En tal sentido, recae la advertencia de Francisco en Evangelii gaudium acerca de ciertas formas de comprender la ortodoxia que participan de la mundaneidad espiritual: "Es una supuesta seguridad doctrinal o disciplinaria que da lugar a un elitismo narcisista y autoritario" (Francisco, 2013, n. 94). De mayor penetración aún es la expresión:

No nos preocupemos solo por no caer en errores doctrinales, sino también por ser fieles a este camino luminoso de vida y de sabiduría. Porque "a los defensores de 'la ortodoxia' se dirige a veces el reproche de pasividad, de indulgencia o de complicidad culpables respecto a situaciones de injusticia intolerables y a los regímenes políticos que las mantienen”. (n. 194)

Como el joven rico de Mateo, podemos complacernos en todo lo que hacemos bien, olvidándonos en la clave de aquello a lo que debemos renunciar, despojarnos y convertir para encontrarnos con los demás y con Dios (Mt 19, 16-30). Sin embargo, no obstante pararnos en ese lugar oscuro de conocimiento, el resultado no es la angustia trágica, sino la alegría de saber que por la Pascua todo ha adquirido sentido.

Pero ¿¿cuál es el resquebrajo de la historia?, ¿đónde se plasma esa herida? Uno de los lugares, sin duda, son los pobres:

Mientras emerge cada vez más la riqueza descarada que se acumula en las manos de unos pocos privilegiados, con frecuencia acompañada de la ilegalidad y la explotación ofensiva de la dignidad humana, escandaliza la propagación de la pobreza en grandes sectores de la sociedad entera. Ante este escenario, no se puede permanecer inactivos, ni tampoco resignados. A la pobreza que inhibe el espíritu de iniciativa de muchos jóvenes, impidiéndoles encontrar un trabajo; a la pobreza que adormece el sentido de responsabilidad e induce a preferir la delegación y la búsqueda de favoritismos; a la pobreza que envenena las fuentes de la participación y reduce los espacios de la profesionalidad, humillando de este modo el mérito de quien trabaja y produce; a todo esto se debe responder con una nueva visión de la vida y de la sociedad. (Francisco, 2017) 
Pero, también, esta herida son los despojados de su tierra, de sus referencias históricas y de sus vínculos familiares. Esas multitudes de desplazados que buscan la paz:

Cada forastero que llama a nuestra puerta es una ocasión de encuentro con Jesucristo, que se identifica con el extranjero acogido o rechazado en cualquier época de la historia (cf. $M t 25,35.43$ ). A cada ser humano que se ve obligado a dejar su patria en busca de un futuro mejor, el Señor lo confía al amor maternal de la Iglesia. Esta solicitud ha de concretarse en cada etapa de la experiencia migratoria: desde la salida y a lo largo del viaje, desde la llegada hasta el regreso. (Francisco, 2018, párr. 1)

¿La cuestión es ortodoxia versus compromiso? (cf. Gutiérrez, 2005, p. 15). A veces, pensamos que está la teología con sus verdades, sus sistemas y sus garantías de identidad colectiva. Nuevos contextos interrogan esos relatos teológicos, no para hacer borrón y cuenta nueva, sino para poder decir una palabra sobre el tiempo que nos toca vivir. Otras veces, nos escondemos en ciertos modelos reflexivos para no tomarnos el trabajo, o no asumir el compromiso, de preguntarnos acerca del paso de Dios en nuestro tiempo.

Esta herida y la decepción ante la Alianza nos ponen ante un escenario similar al del pueblo de Israel en el exilio. Israel debió recrear su fe, comprendiendo la Alianza hacia las profundidades del misterio y renunciando a la forma "recíproca” y mecánica de retribución; desde ahí el pueblo santo creía gozar de las inmunidades de la trascendencia. La teología del posexilio, primero en el profetismo y luego en la asunción de las tradiciones históricas y las proféticas en la apocalíptica, nos muestran que los lenguajes sobre Dios se recrean y acrisolan en contextos de crisis, en los que la elección divina es puesta en dudas y se desmantelan los ídolos que construimos para justificarnos o para darnos seguridad.

Uno puede preguntarse ¿̇en el exilio se hace trizas la ortodoxia de Israel? O es que Israel ingresa en los aspectos más profundos de Dios que siempre está presente en su pueblo. Este Dios que siempre está (Ex 3, 14), para no ser un Dios violento y exclusivo, tiene que serlo de todos. Y eso es lo que leemos, entre otros textos, en Isaías 56.

Israel comprendió a Dios como su defensor, aquel en quien tenía garantizada su supervivencia y que ponía como garantía de la fidelidad a la Alianza una tierra donde podían ser un pueblo. Un pueblo que no era una creación humana constituida por una magnitud exclusivamente sociológica. Ese pueblo era la Qahal Yavé (Asamblea de Dios). La tradición judía veía en la qahal del Sinaí el acontecimiento de la renovación de la humanidad como tal, una reconstitución de su condición adánica antes del pecado, una suerte de reanudación de la creación. Esta expresión qahal significaba aspectos de intensa densidad que es preciso señalar. Cuando el Deuteronomio evoca la asamblea del pueblo de Dios el día de la promulgación de la Ley o de la Alianza, utiliza la expresión qahal (Dt 9,$\left.10 ;{ }^{2} 18,10\right)$. El contexto está dado por la convocatoria señalada en Dt 4, 10: "reúneme al pueblo para que yo les haga oír mis palabras a fin de que aprendan a tenerme mientras vivan y se acerquen a sus Hijos", lo cual señala que este qahal no es una convocatoria simplemente ritual y, menos aún, exclusivamente política, sino que expresa a un pueblo donde se da el cumplimiento de la voluntad de Dios, como queda señalado en Dt 10, 12-11, 17, un pasaje fundamental

2 "El Señor me dio entonces las dos tablas de piedras escritas por el dedo de Dios; en ellas estaban todas las palabras que el Señor les dijo en la montaña, en medio del fuego, el día de la asamblea”. 
centrado en la exigencia de amar a Dios y cumplir sus mandamientos, no simplemente como disposiciones de carácter ritual, sino que lo que Dios espera de su pueblo es la transformación interior de la persona.

Pero Babilonia arrasa con esta esperanza. Se pierde la tierra y se disgrega el pueblo. Se desarrolla una estrategia de disgregación y dominación. Sin embargo, la literatura bíblica posterior da cuenta de una revolución del lenguaje que procede de una experiencia interior inédita: esa tierra será universal y se dará un reino al pueblo que no pasará jamás, como atestigua el capítulo 2 del libro de Daniel. El proceso final da como resultado una comprensión de las promesas que exige la consolidación de cuatro elementos fundamentales. Por un lado, Yavé no será el "más grande de todos los dioses" como proclama el Salmo 94, sino el único Dios que invita a todos los pueblos. Este universalismo lleva a consolidar los rasgos de una trascendencia y omnipresencia divina nunca antes elaborados en la teología judía. A su vez, esta trascendencia, que hubiera podido hacer de Dios un soberano que asedia a sus hijos, lo revela misericordioso hasta el extremo de renunciar a los sacrificios y cultos que no tengan al pobre, al extranjero y a la viuda como ofrendas fundamentales a su señorío. Pero, por otro lado, y abrazando todas estas notas, este Dios presente en todos los pueblos y dispuesto a convocar a todos a la salvación, no se vuelve un objeto manipulable garante de una nueva alianza centrada en la salvación de todos y sellada en el corazón, sino, como amarga y jubilosamente aprende Job, se vuelve un misterio a nuestra exigencia de evidencias. Una tensión sobresaliente se acrisola entonces: Dios, que pide optar por Él en los que más sufren y a la vez que llama a este desmesurado realismo, se vuelve un misterio que no podemos alcanzar. Su única evidencia es el rostro de los que sufren, allí está Él. Ya la historia no se puede interpretar desde la lógica jurídica de la doble retribución, que da certezas y garantías, pero reserva el conocimiento de Dios a los "cumplidores". Ni desde el pesimismo, al que solo le cabe esperar que lo que se repita de lo que se dio no lo haga con rencor renovado. Es el misterio, que nos expone a la noche oscura de no poder tener todas las certezas, vivido desde la garantía del amor de Dios.

Esta tensión se hace patente en Jesús: él es el Reino mismo entre nosotros, como nos recuerda Orígenes en su célebre fórmula autobasileia estí (Cristo mismo es el Reino). ${ }^{3}$

Pero Jesús nos revela una tensión que está en el centro de nuestra comprensión de Dios. Por un lado, nos enseña que "el que me ha visto a mí ha visto al Padre" (Jn 14, 9), pero parte dejando su Espíritu, y no lo veremos más.

Ante la pretensión de Tomás que cree que lo fundamental en el seguimiento está en ver la evidencia del Señor, Jesús aclama "felices los que crean sin haber visto" (Jn 20, 19-29).

A su vez, Mateo nos enseña que el Señor advirtió que lo que han hecho con sus hermanos más pequeños con él lo han hecho (cf. Mt 25, 40). ¿Dónde te hemos visto para que podamos hacer todas esas obras por ti? En ellos. Juan nos recuerda este memorial en el lavatorio de los pies y en el mandamiento del amor: "lo que les mando es que se amen los unos a los otros" (Jn 15, 17). Siete veces aparece la palabra

3 "Así como es la misma sabiduría y la misma justicia y la verdad misma ¿̨no ha de ser por la misma razón, Él mismo, el Reino? (kai e autobasileia) [...] puedes decir que Él mismo es el Reino (autobasileia esti)" (In Matt. hom. 14, 7; PG 13, $1198 \mathrm{BC})$. 
amor o sus derivados en el pasaje de Jn 4, 7-10 en el que se vincula al conocimiento de Dios con el amor, porque Dios es amor.

Nuevamente el mandato de poner la mirada en el otro, en el prójimo, para conocer a Dios. ¿Cómo hacer de la teología una narración que salve a Dios de la aprehensión y, por tanto, asumiendo la analogía como una forma posible de crear una mediación del lenguaje, pero no dejarlo en el simple plano de un discurso dogmático que no pueda sostener el empeño profético al que estamos llamado? ¿Es posible que esta dialéctica presente en la historia preñe también la analogía como esta ha inundado las explicaciones del sufrimiento y del dolor de Dios? Sin contar con los esfuerzos especulativos de la teología posterior, Ignacio de Antioquía tuvo la osadía de hablar de la sangre de Dios derramada por nosotros.

Y uno puede preguntarse, si Dios es pura perfección, ¿por qué no puede contener en Él la historia, y por ello encarnarse, y por eso sangrar y sufrir? Es que Él contiene la razón de cada una de estas realidades en su amor, y también las de toda la historia trascendiéndola y estando presente en toda ella. Dios puede sufrir por nosotros, como amor puro, precisamente por no poseer carencia ni nada en sí que sea dolor.

Es verdad que la teología de las personas desarrollada más tarde, y sobre todo una teología de la naturaleza divina separada de la de las personas, condujo a mantener la pasión como algo que aconteció en el Hijo en su devenir histórico. Pero también es verdad que las personas se distinguen realmente entre sí, aunque de la naturaleza solo con distinción de razón, según enseña santo Tomás. De modo que no hay naturaleza divina sin Trinidad. Y no hay personas sin todo su acontecer. Esta perspectiva quiso ser integrada por primera vez por Joaquín de Fiore, sin mucha fortuna, quien la teología posterior lo volvió más un réprobo que un piadoso hombre de Dios. Joaquín, como antes también Guillermo de Ockham, era heredero de Francisco; no podía pensar sin referirse al concreto y allí se encontraba el misterio más profundo de la verdad revelada. Allí anidaba Dios para nosotros. Independiente de las dificultades de su pensamiento y de las advertencias del IV Concilio de Letrán sobre sus enseñanzas, esta intención es, en nuestro tiempo de dificultad para el Dios de los cristianos, una tarea a reemprender. El punto de partida de Fiore, como el de Agustín, es la Revelación; pero, mientras que para Agustín la figura central en su interpretación de la historia es Cristo, para de Fiore es el misterio trinitario. La Trinidad se refleja en el proceso histórico y la historia es el camino para llegar a la perfección de la Ciudad de Dios. Esto lo llevó a asociar, casi hasta la identidad, la trascendencia y la historia por la pretensión de mostrar al Reino presente entre nosotros. Quiso romper los dualismos saliendo por la única puerta que veía abierta, y que no fue la mejor, para decir algo verdadero: el Reino está presente entre nosotros. Sin embargo, no podemos olvidar la pasión dedicada a manifestar la presencia de Dios en la historia. Su límite no puede hacernos desconocer su legítima preocupación por hacer notar que Dios anticipa entre nosotros su plenitud y su amor. La tensión entre la Trinidad y la historia nos pone ante una exigencia reflexiva mucho mayor que pensar el misterio de la historia asociado con Jesús, cuya evidencia escrituraria queda indudablemente atestiguada. Pero ¿quién es el Dios que es Jesucristo? El debate trinitario que transita sobre el andador de la cristología da cuenta de que en los primeros cuatro siglos se alcanzó a ver la seriedad de este problema.

Me gustaría en este momento detenerme brevemente en un concepto complejo, la verdad, y luego en la historia de una asociación que ha sido determinante para nuestros lenguajes teológicos: el ser y Dios. 


\section{La verdad más allá del ser de Parménides y del uno de Plotino}

Creo que el uno de Parménides ha triunfado como forma de expresarnos teológicamente, aun cuando las mejores páginas de san Agustín se dedican a hablar de la esencia divina reflexionando sobre las analogías trinitarias intrasubjetivas (mente, inteligencia, voluntad; memoria, inteligencia, voluntad; amado, amante, amor). También, a pesar de que Ricardo de San Víctor logra alcanzar una definición de la persona superando la boeciana que incluía la sustancia individual, inaplicable para Dios. O cuando santo Tomás habla de la persona como relación subsistente, reconciliando el momento absoluto y el personal en el misterio de la intimidad divina. Aun también cuando Rahner y Kasper en una perspectiva discutible pensaron la dimensión personal de toda la Trinidad recurriendo al Padre como aquel en quien se dice todo lo común. $\mathrm{O}$ a pesar de que Gisbert Greshake ha ofrecido una notable reflexión de la unidad recurriendo a la antigua categoría de la perijóresis, volviendo a la comunión y al amor los datos distintivos de la esencia de Dios. Si esa esencia es amor, no puede ser una antes que trina. Por ser la más perfecta unidad es plural, pues la perfección del amor exige que sea compartido entre varios, como recordaba San Víctor en el capítulo 3 del De Trinitate. ${ }^{4}$

Quizá ha costado menos ver el peligro de disgregación presente en la unidad que el de totalitarismo en una unidad en la que su cualidad última es lo uno. Esto tal vez como rémora de una visión determinada de la verdad. Los trascendentales del ser califican mutuamente, de modo que la pretensión de lo uno separado ha arrastrado una visión de la verdad monolítica. En referencia a ello, también hemos comprendido la autoridad y la forma de organizar las instituciones. Dios no es una dinámica confusa y evanescente, pero tampoco el uno de Parménides. Es el misterio de una unidad de amor personal de iguales. Y forma parte de su misterio querer asociarnos a esa identidad en su diversidad y desde nuestra libertad.

Creo que aquí es necesario aclarar brevemente una cuestión. Es lícito hacerse la pregunta desafiante sobre la verdad. ¿Qué es la verdad? La teología ha tenido un diálogo fecundo con la filosofía que le ha permitido enriquecerse con lenguaje, método y una visión muy amplia del mundo. Pero, como efecto de ese diálogo, ha tenido la tentación de identificar la verdad con lo abstracto. Esta perspectiva se profundizó en los últimos siglos con la tendencia a reducir la verdad a la doctrina enunciada, olvidando el sabio consejo de santo Tomás: "actus credentis non terminatur ad enuntiabile sed ad rem". 5

4 "Si hubiese una sola persona en aquella verdadera divinidad, no obstante, también podría tener caridad para con su creatura, y ciertamente lo tendría. Pero no podría tener ciertamente la suprema caridad para con una persona creada. La caridad sería desordenada si supremamente amara a quien supremamente no debiera serlo. Es imposible que sea desordenada la caridad en aquella bondad supremamente sabia. Por eso, la persona divina no pudo tener una caridad suprema para con una persona que no fue digna de una suprema dilección. Para que la caridad sea suprema y supremamente perfecta, es necesario que sea tan grande que no pudiese haber ninguna mayor que ella, es necesario que también sea tal que no pudiese haber nada mejor que ella. Mientras que quien no ama nada mayor que sí mismo, él, a quien para consigo tiene amor privado, demuestra que el grado supremo de la caridad todavía no aprendió. Pero la persona divina no tendría ciertamente a quien amar dignamente como a sí misma, si absolutamente no tuviera una persona codigna. No sería codigna de una persona divina una persona que no fuese Dios. Por tanto, para que en aquella divinidad pudiera tener lugar la plenitud de la caridad, fue necesario que alguna persona divina no careciera de participación de una persona codigna, y por eso mismo, divina. Por eso, ve cuánto demuestra por una razón fácil que en la verdadera divinidad no puede faltar la pluralidad de personas" (De Trinitate 3, 2).

5 S. Th. II-II, q.1 a.2 ad secundum. El acto creyente no termina en el enunciado, sino en la cosa enunciada. 
La verdad se redujo a principios y quedó huérfana de su carácter dialogal. Esto se fortaleció por el hecho de que grandes corrientes de la filosofía moderna pretendieron monopolizar el discurso sobre Dios y, como contrapartida, la teología se esforzó por desarrollar la razonabilidad de su quehacer. Este proceso separó, sin pretenderlo, la fe formulada de la fe creída. De este modo, el criterio de objetividad se configuró como una seguridad intelectual organizada en función de evidencias empíricas o razonables o magisteriables.

Pero vale la pena preguntarse si estos criterios de objetividad, que pueden caracterizar el mundo de las ciencias, que a partir de la experimentación o la argumentación llegan a una conclusión aceptable, alcanzan para hablar de la verdad de la fe. Esa verdad no es un enunciado, sino la comunión con Dios y con los hermanos. Esa es la verdad: que Dios, que es comunión, nos llama a la comunión con Él y entre nosotros. Y si hay criterio "empírico" aceptable para validar esta verdad, ese es que lo que hayamos hecho con nuestros hermanos más pequeños lo hemos hecho con Él. Si hay una experiencia de esta verdad, es aquella que está movida por la salida de sí dada por su razón formal que es la caridad.

La objetividad abstracta no salva ni da plenitud. El gran desafío, entonces, como enseńaban autores como Guardini, es interpretar la verdad como lo viviente, el hombre viviente y el Dios viviente. Lo viviente y sus tensiones. Allí se encuentra el desafío de la verdad.

Considero que es desde aquí de donde se entiende la afirmación de Francisco, en la carta que dirigió a Eugenio Scalfari, del periódico La Repubblica, el 4 de septiembre de 2013, en la que responde a aquella que el periodista italiano le dirigió en julio del mismo año:

Me pregunta si pensar que no hay nada absoluto y, por tanto, tampoco una verdad absoluta sino solo una serie de verdades relativas y subjetivas, es un error o un pecado. Para empezar, no hablaría, ni siquiera para quien cree, de verdad "absoluta", si se entiende absoluto en el sentido de inconexo, que carece de cualquier tipo de relación. Para la fe cristiana, la verdad es el amor de Dios por nosotros en Jesucristo. Por tanto, jla verdad es una relación! De hecho, todos nosotros captamos la verdad y la expresamos a partir de nosotros mismos: desde nuestra historia y cultura [...] Eso no quiere decir que la verdad sea variable y subjetiva, todo lo contrario. Más bien indica que se nos da siempre y solo como camino y vida [...] Con otras palabras, la verdad, siendo una sola cosa con el amor, requiere humildad y apertura para buscarla, acogerla y expresarla.

Estas consideraciones de Francisco (2013) nos permiten comprender mejor lo que afirmó en el número 194 de la exhortación Evangelii gaudium:

Los aparatos conceptuales están para favorecer el contacto con la realidad que pretenden explicar y no para alejarnos de ella. Esto vale sobre todo para las exhortaciones bíblicas que invitan con toda contundencia al amor fraterno, al servicio humilde y generoso, a la justicia, a la misericordia con el pobre. Jesús nos enseñó este camino de reconocimiento del otro con sus palabras y con sus gestos. ¿Para qué oscurecer lo que es tan claro?

La advertencia no nos exime del pensamiento, pero nos exige revisar aquellos discursos que ponen el fin en el análisis, absolutizan la opinión y nos distancian de la exigencia evangélica por la historia concreta. Esta visión metafísica posee en el concepto casa común de Laudato si'su versión cosmológica, y 
en la propuesta de un "prójimo sin fronteras" de Fratelli tutti su perspectiva ética (Francisco, 2020, nn. 80-82). Además, estas consideraciones nos conducen a estimar que "los principios morales elementales y universalmente válidos pueden dar lugar a diversas normativas prácticas. Por eso deja siempre un lugar para el diálogo" (n. 214).

Sin embargo, los arrastres de una cosmovisión de lo Uno como perfecto absoluto continúan incidiendo en todas nuestras consideraciones. Debemos preguntarnos en qué medida no permanecemos en un subordinacionismo ontológico, en la clave plotiniana, en el que el Logos, si bien revela las perfecciones del Uno, lo exime de la diversidad interior. Pasado a la cristología sería eximirlo de la pasión. La doctrina de Plotino "procede de la oposición entre la pluralidad empírica y el fundamento ontológico de esta última en el Uno trascendental que se encuentra más allá de todo ser y, por consiguiente, no puede ser objeto de ninguna definición positiva" (Bulgákov, 2014, p. 55).

La asociación Dios-ser tuvo en este sentido un aspecto positivo que se constituyó en la posibilidad de hablar positivamente de Él. Lenguaje definitivamente establecido por los padres capadocios; sin embargo, poseyó un límite al que me gustaría referirme brevemente.

\section{El Dios que siempre está}

Paul Ricoeur (1976, pp. 337-356) da cuenta de la herencia provocada por la traducción de Ex 3, 14 y su compleja historia receptiva, inaugurada por la Septuaginta que tradujo 'ehyeh 'aser 'ehyeh (היהא רשא היהא ${ }^{6}$ como ego eimi ho on ('E $\gamma \omega \dot{~ \varepsilon i ̉ \mu ~ o ̀ ~ o ̈ v) . ~}$

Esta traducción escondía una dificultad profunda: la de equiparar la noción de ser aplicada a Dios en el texto original a la noción de ser en el pensamiento griego. Una visión más relacional, dinámica y viva; la otra convocada a una comprensión más abstracta, lógica y estática.

La paradoja, como veremos, es que las más audaces consideraciones ontológicas de los pensadores medievales se encuentran en completa oposición a una concepción del ser "abstracta" o "esencialista", precisamente por el impacto ejercido por Ex 3, 14. En este sentido, por ontológicos que puedan ser, esos filósofos están de acuerdo en el rechazo de toda pretensión de tipo intelectualista (Ricoeur, 1976, p. 341).

Habitualmente se ha acusado a la tradición escolástica de operar de modo decisivo este recorte semántico a la comprensión de Dios. Sin embargo, baste pensar la evolución de la noción de persona para reflexionar su uso trinitario y el impacto decisivo para una visión relacional en las propuestas de Ricardo de San Víctor y santo Tomás de Aquino, para darnos cuenta de lo limitada de esa perspectiva.

De ahí que es importante considerar que, con su doctrina de Dios como el ser subsistente mismo,

6 Yo soy el que soy. 
consigue Tomás salvaguardar la trascendencia de Dios respecto del mundo. Pues entre el ser-ser de Dios y el tener-ser de las criaturas existe una infinita diferencia cualitativa. Por consiguiente, con la definición de Dios como ipsum esse subsistens no se encuadra a Dios en un orden ontológico que engloba a Dios y al mundo; antes bien, Tomás afirma de manera expresa que Dios no pertenece a ningún género, no está incluido en el ser. Es infinitamente superior a cualquier otra realidad. Por otra parte, con su definición de Dios, Tomás, a diferencia del neoplatonismo, afirma también la inmanencia de Dios en el mundo, que viene dada con la idea de creación. (Kasper, 2013, pp. 229-230)

De este modo, la definición de Dios como ipsum esse subsistens persigue cabalmente distinguir a Dios del ens commune. Que se le pueda reprochar a Tomás un olvido del ser en el sentido de Heidegger es, cuando menos, muy controvertido (Kasper, 2013, p. 231). Ex 3, 14 es la historia de una vocación: Moisés deberá legitimar su misión con la apelación a un Dios cuyo nombre es simplemente... ¿el que es? Dios le promete su presencia, pero Moisés insiste en que deberá decir el nombre del Dios que lo envía. Dios responde: 'ehyeh' aser 'ehyeh.

De algún modo, será el Nuevo Testamento el que mejor aclimatará el verbo griego "ser" (einai: cíval) al marco bíblico. Aquí sobresale el libro de Apocalipsis y el Evangelio de Juan como colaboradores en esta fusión de vocabularios. Leemos en Ap 1, 4: "Aquel que era, que es y que ha de venir". No puede haber dudas de que esta fórmula repetida cinco veces es una nueva traducción de Ex 3, 14. Y el Evangelio de Juan establece: "Antes que Abraham existiera, yo soy" (Jn 8, 58). Estos usos del verbo einai son tanto más significativos cuanto se extienden de Dios a Cristo (Ricoeur, 1976, p. 345).

Pero, indudablemente, si hay algo que nos despierta este nombre, tanto en su expresión original hebrea como la traducción griega "einai (cíval)" y la latina ese es la experiencia de un doble sentido. Por un lado, porque se afirma positivamente que Dios es garantizando fidelidad y eficacia ante su pueblo; por otro, y de forma intensa, "el de una revelación negativa que disocia el Nombre de aquellos valores utilitarios y mágicos referentes al poder con que ordinariamente se le asociaba” (Ricoeur, 1976, p. 346). El Dios que se revela a Moisés no puede ser aprehendido por una categoría que lo aprisione, que lo haga objeto de manipulación religiosa o de mera anticipación humana. Las tentaciones del racionalismo, la magia y las éticas que reducen la moral de la bienaventuranza a prescripciones fariseas son alguna de las formas de manipulación.

Hay otras que son aquellas que intenta enseñorear la voluntad humana frente a la de Dios enmascarando este propósito en falsas sacralizaciones. Este disfraz semántico configura uno de los elementos más complejos de lo que el papa Francisco llama en 2013, ante los obispos del Consejo Episcopal Latinoamericano (Celam), en el punto 4 del discurso, "la iglesia tentada". En ese texto, el papa no anticipa realmente lo que va a desarrollar. Se espera más bien desde el título una exposición más subjetiva de aquellos elementos que tientan al discipulado misionero. Sin embargo, pasa a hablar de la iglesia tentada girando la argumentación de las dificultades que nos llevan a evadirnos de nuestra misión a aspectos estructurales, sistémicos e institucionales. Estas tentaciones son "la ideologización del mensaje evangélico [...] el funcionalismo [...] el clericalismo", y son desarrolladas en algunos de sus aspectos generales en ese discurso del papa; sin embargo, todas dejan en evidencia que la principal tentación de la Iglesia es utilizar lo divino como instrumento de poder, constituyendo ideología, reduciendo a Dios a mero principio absoluto, desplegando una visión providencialista que salva la omnipotencia divina a expensas de la densidad de la salvación 
histórica y haciendo de Dios un primero en el orden de las causas, e instaurando una clase sacral que posee privilegios que derivan de su cercanía con lo divino.

Como consecuencia del desplazamiento del problema teológico a la filosofía, los pensadores modernos enmarcaron el problema de Dios dentro de los paradigmas filosóficos, desoyendo, de algún modo, la advertencia kantiana que poco deja para hablar de Dios. Pero si Kant exageraba la imposibilidad, la filosofía posterior exacerbó el dominio. Al final de Identidad y diferencia, Heidegger (1988) se enfrenta a ese concepto de Dios sobre el que todo puede ser dicho, previsto y analizado, y dispara "ante ese Dios nadie puede danzar, rezar, llorar [...] háganle un favor a Dios, dejen de hablar de él".

Es la tentación de hacer de Dios simplemente un ser absoluto y de la teología el saber que puede objetivarlo. Y podemos entrever la deformidad de los servicios eclesiales cuando se vuelven la garantía cierta de que ese saber y obrar objetivantes, ejercidos ministerialmente, son adecuados al verdadero Dios.

No se deben olvidar, volviendo a Ex 3, 14, algunas convicciones que poseía san Agustín al considerar la pretensión de "intuir" intelectualmente a Dios: "El qui est no da acceso a ningún quid est. Ser alguien no significa ser algo" (Ricoeur, 1976, p. 350). Pero no debemos tentarnos con el prejuicio antiintelectual de pensar que nada es posible a la palabra sobre Dios. Sería reducirlo a un numen misterioso a la vez que someterlo al orden de un profetismo en el que algunos iluminados y revestidos de poderes especiales tienen la primicia de la voluntad divina. Ser es existir en cuanto tal. "Es para señalar esta trascendencia tanto interior como exterior, por lo que en sus últimos diálogos Agustín entiende el esse de un modo más específico, como ipsum ese y hasta como idipsum esse" (Ricoeur, 1976, p. 350).

Precisamente por las dificultades del término aludido, santo Tomás llevará hasta el extremo la purificación conceptual de Dios, advertirá con pudor acerca de la inaccesibilidad de la naturaleza íntima de Dios, priorizará el momento gratuito del don en el vínculo con él y mostrará desde sus conocidas cinco vías que la existencia de Dios no repugna a la inteligencia.

La traducción del nombre de Dios a ipsum ese per se subsistens, clásica fórmula tomasiana, si bien intensamente ontológica, contiene la reserva fundamental que es necesaria para aplicar el término ser a Dios: ser en Dios se dice de modo absolutamente propio de él.

Ricoeur, al final del artículo evocado, a partir de la crítica de Marion (2010) en Dios sin el ser, en que el gran fenomenólogo francés ha advertido que el ateísmo demostró la vanidad de toda determinación conceptual de Dios en la cual se desarrolla otra versión de la idolatría, que es la idolatría conceptual (Ricoeur, 1976, p. 360).

Por otro lado, es necesario no olvidar la gran conquista especulativa de santo Tomás al definir a la persona, en Dios, como "relación subsistente". Aquello más allá de lo que poco se puede decir, pues pensar que lo suprapersonal es superior, es una tentación metafísica que conduce al vacío (cf. Kasper, 2013, p. 235), es relación y subsistente. Pero, además, Tomás nos enseña que allí está lo verdaderamente distinto en Dios, ya que las personas se distinguen realmente entre sí, mientras que solo con distinción de razón de la esencia. ¿A cuántas otras cosas nos abren esas consideraciones? ¿Cómo no pensar en ellas y estimar que ser persona en Dios es la eterna capacidad de entregarse, de vaciarse generosamente y de estar 
eternamente abierto a la siempre novedosa y presente existencia del otro? Allí está el fundamento de la kenosis del Hijo y de la gloria silenciosa del Espíritu en la historia sin el cual no podríamos proclamar que Cristo es el Señor (cf. 1 Cor 12, 3).

La ideologización de Dios es el apartamiento conceptual del Dios verdadero, que enmascara su rostro y lo reduce a las necesidades del usuario. Marion (2010) invita a anticipar la teología del don a la del ser para acceder al Dios revelado por el Evangelio de Juan: Dios es amor. De ahí la importancia del ejemplo que ofrece Francisco (2020): "no hacía la guerra dialéctica imponiendo doctrinas, sino que comunicaba el amor de Dios" (n. 4).

Esta opción no será la denostación de la apelación a una visión ontológica de Dios. Ni siquiera podemos afirmar de Él el amor sin utilizar la cópula verbal ser: es amor. La plenitud del acto de ser se identifica con el amor. Y es aquí donde la sobreabundancia de la misericordia inunda la comprensión de Dios, a través de la mediación del don y del perdón y la relación con el hermano, reconociendo el llamado a extender la mano al que queda al margen de todo derecho de justicia, por ser mi victimario o porque nada puede dar a cambio. La mirada de Francisco sobre las periferias no es solo un recurso pastoral, sino otro modo de ver la realidad.

\section{Las personas y la forma de vivir de modo personal lo común}

Los concilios de Nicea I y de Constantinopla I nos dan al respecto algunas enseñanzas particularmente

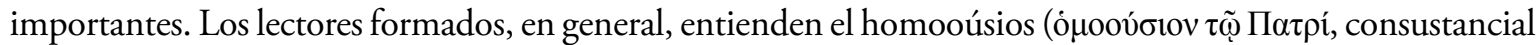
al Padre) como el aporte más decisivo del primer niceno. Creo, sin embargo, que observando en profundidad el texto y abriéndonos a su comparación con la definición constantinopolitana, nos encontraremos con aspectos más ricos que esa simple evidencia. Más aún, esa única forma de ver la identidad de naturaleza entre el Padre y el Hijo y el Espíritu Santo, referidas a simples conceptos explicativos, no ha sido favorable para la comprensión de otros aspectos de la teología trinitaria, como el célebre teologúmeno de san Agustín referido al origen del Espíritu Santo: el Filioque. El discurso teológico se orientó desde estas definiciones más bien a privilegiar la seguridad de una esencia inmutable ante la inquietante riqueza del misterio trinitario. Esto realizado a través de un gran tributo denunciado por Bruno Forte como "el exilio de la Trinidad".

Porque, si es verdad afirmar que en Dios las personas son relaciones subsistentes, también sería conveniente pensar que la sustancia común es relacional. De algún modo, esto último fue consagrado por la teología contemporánea al afirmar que Dios es comunión. Si bien la trayectoria interpretativa posterior se afianzó en perspectivas sustancialistas, la convicción de la idéntica naturaleza divina promulgada por estos dos concilios del siglo IV fue relacional y no sustancialista. Tanto el homooúsios niceno como la expresión del constantinopolitano I "que con el Padre y el Hijo reciben la misma adoración y gloria", expresión tomada de la teología de Basilio de Cesarea, declaraban la divinidad de los tres en clave relacional. Por un lado, expresa con nombres distintos las relaciones del Hijo con el Padre ( del Padre generado) y la del Espíritu Santo con el Padre ( procedente) de inspiración joánica. 
Por otro lado, se afirma de ambos tópicos diversos para hablar de Dios. Para hablar del modo como se da la identidad divina del Hijo, se utiliza el homooúsios; pero, para hablar del mismo misterio dicho del Espíritu Santo, se afirma "que con el Padre y el Hijo recibe la misma adoración y gloria". Olvidar esta dinámica nos conduce a una visión estática que dista mucho de la pretensión del texto conciliar (cf. Fernández, 2013, p. 14).

Es interesante, además, constatar que tanto Atanasio como Basilio de Cesarea, y finalmente el texto constantinopolitano, para ser fieles al uso escriturístico, no llaman al Espíritu Santo "Dios", sino que dicen de él que es "igual en adoración y gloria". Sí afirma Nicea del Hijo que es "Dios de Dios" y "Luz de Luz", no solo que es Dios. Dios es visto en el Hijo y el Hijo es recordado e iluminado para nosotros por el Espíritu. Él es la memoria de Dios, enseñaba Basilio de Cesarea en el Tratado del Espíritu Santo.

Y de la misma manera que podemos contemplar al Padre en el Hijo, así también podemos ver al Hijo en el Espíritu. Por ello, adorar a Dios en el Espíritu es lo mismo que adorarlo en la luz o en la verdad, como se puede deducir de las palabras que el Seńor dijo a la samaritana. De la misma manera que decimos que hay que adorar al Hijo, como imagen de Dios Padre, también debemos decir que hay que adorar al Espíritu, pues posee y refleja en sí mismo la divinidad de Cristo. Así pues, por la iluminación del Espíritu, contemplamos propia y adecuadamente la gloria de Dios, en tanto que por la impronta del Espíritu llegamos a aquel de quien el mismo Espíritu es impronta y sello. ${ }^{7}$

No podemos conocer a Dios sino por su misma luz. Esto no solo discute la pretensión de los pneumatómacos, sino también la de las gnosis que enseñan alcanzar el conocimiento divino por un ascenso de la inteligencia.

La clave para corrernos de una interpretación cosificante de estas fórmulas es advertir la intencionalidad salvífica de sus afirmaciones. En este sentido, me parece acertada la afirmación de Meyendorff (1989), cuando comentando De incarnatione Verbi, de Atanasio, afirma:

El mensaje de Atanasio fue que solo Dios mismo podría apropiadamente ser visto y adorado como Salvador. De esta manera, la identidad divina de Jesús (consustancial) con el Padre no era una cuestión de verdad abstracta o puramente teológica, sino que indicaba la miseria de la humanidad caída, mortal, que no podía salvarse a sí misma ni ser salvada por otra creatura.

Este argumento está presente en un conmovedor texto De incarnatione Verbi: "Para mostrarse era suficiente aparecer y asombrar a aquellos que lo veían, pero para cuidar e instruir hacía falta no solo venir, sino meterse al servicio de aquellos que estaban en la pobreza y mostrarse de una manera que pudieran tolerar los indigentes". ${ }^{8}$

No tiene sentido evangélico hablar para aplastar. Estos textos nos muestran que el Dios del que sabemos algo es del que nos salva.

7 Basilio de Cesarea, Liber de Spiritu Sancto PG 32, 186.

8 PG 25. 


\section{La permanente tentación idolátrica}

La ambición por controlar a Dios va junto con la tentación de quitarle su carácter personal. Persona, afirmaba Ricardo de San Víctor, es "esse incommunicabilis" (De Trinitate, L3). Esto significa que "la categoría de 'persona' salvaguarda [...] el carácter no disponible y oculto que Dios conserva en la revelación de su nombre" (Kasper, 2013, p. 235). A su vez, la condición encarnada de Dios es la que nos salva de la mundaneidad como forma de reducir lo divino a nuestras conquistas temporales (cf. Moore, 2020, p. 4). El Dios abstracto y desencarnado, con su neutralidad histórica, garantiza una experiencia de libertad humana que hace de lo mundano el reino absoluto de la voluntad.

En los números 94 y 95 de Evangelii gaudium, Francisco (2013) nos advierte sobre dos maneras profundamente emparentadas de alimentar la mundaneidad: "la fascinación del subjetivismo y la fe encerrada del gnosticismo". Sobre ambas nos advierte la carta Placuit Deo de la Congregación para la Doctrina de la Fe, en los números 13 y 14.

El papa, en 2013, en su visita al Brasil, se dirigió al Comité Ejecutivo del Celam hablando de la Iglesia tentada: por las ideologizaciones, los funcionalismos y los clericalismos. Debemos con sinceridad enfrentar en nosotros esas fuerzas miméticas que nos impiden vincularnos al Dios verdadero cuando nos volvemos siervos de una idea, una función o una lógica de casta que termina haciendo del poder un fetiche (cf. Retamozo, 2007, p. 109).

En este sentido, los lenguajes sobre Dios deben recuperar la relacionalidad y tomar cuenta de los ídolos construidos como proyecciones de nuestra autosatisfacción intelectual, nuestra vanagloria de poder, nuestra pretensión de convertir un servicio en un sinnúmero de privilegios (cf. Noemi, 2007, p. 441).

Cierta razón tenía Feuerbach (1956, cap. 2) al afirmar en Das Wesen des Christentums que Dios no nos había creado a su imagen y semejanza, sino que nosotros lo habíamos hecho a nuestra imagen y semejanza. ${ }^{9}$ Si tomamos esas afirmaciones como una advertencia a una forma de comprender a Dios en los límites de nuestra naturaleza, con las fronteras de nuestra naturaleza y para satisfacer las necesidades de nuestra naturaleza, podremos descubrir una verdad: a veces no es de Dios de quien hablamos sino de nosotros, y son nuestras ambiciones a las que otorgamos carácter sagrado (cap. 12). ${ }^{10}$

De ahí que las Escrituras nos enseñan que la projimidad es la forma más adecuada para encontrar a Dios entre nosotros. La "salida", de la que habla Francisco. Iglesia en salida para ser imagen de Dios que es relación, que es para nosotros envío (cf. Azcuy, 2020, pp. 285-286).

9 "Lo que en las religiones anteriores se consideraba como objeto, ahora es algo subjetivo, es decir, lo que antes se creía y se adoraba como Dios, se sabe ahora que es algo humano. La religión anterior es idolatría para la posteridad: el hombre hizo adoración de su propia esencia”.

10 "La religión, por lo menos la cristiana, consiste en el comportamiento del hombre para consigo mismo o, mejor dicho, para con su esencia; pero considerando a esa esencia como si fuera de otro. La esencia divina no es otra cosa que la esencia humana". 
Francisco, en el número 97 de Evangelii gaudium, afirma: “¡Dios nos libre de una Iglesia mundana bajo ropajes espirituales o pastorales! Esta mundaneidad asfixiante se sana tomándole el gusto al aire puro del Espíritu Santo, que nos libera de estar centrados en nosotros mismos, escondidos en una apariencia vacía de Dios!".

Finalmente, no hablar de Dios como de un argumento del que uno quiere convencer. Dios no es contenido de una realidad (cf. Albado, 2020, p. 31), sino que es la realidad de sí mismo y fundamenta la nuestra, aunque no la explica, ya que un Dios que sustituye a las ciencias es muy poco Dios.

Nuestro tiempo debe resolver la crisis entre destino individual y destino comunitario. La experiencia de la persona y los modelos trinitarios de comunión son un camino, un diseño que debemos recorrer (cf. Tomichá, 2019, p. 118). Para ello, hace falta abandonar un poco la construcción de nuestras certezas solitarias y salir de nuestras zonas de confort para levantar, como el samaritano (cf. Sobrino, 2007, p. 134), al que nada puede dar desde la herida en la vera del camino; esta es la forma de sentar las bases para un lenguaje integral.

\section{Referencias}

Albado, O. C. (2020). Teología y pandemia: hacia un cambio de modelos culturales. Teología, 57(131), 29-36. Recuperado de https://erevistas.uca.edu.ar/index.php/TEO/article/view/3036

Azcuy, V. R. (2020). El desafío inclusivo de la espiritualidad desde Evangelli gaudium y Fratelli tutti. Poliedro: Revista de la Universidad de San Isidro, 3(1), 284-293.

Bloom, H. (2006). Jesús y Yahvé: los nombres divinos. Buenos Aires: Taurus.

Bons, E. y Legrand, Th. (Ed.) (2011). Le monotheísme biblique: évolution, contextes et perspectives. París: Les Éd. du Cerf.

Bulgakov, S. (2014). El Paráclito. Salamanca: Sígueme.

Dreher, M. (2017). Redescubriendo la teología de la cruz de Martín Lutero en el contexto de la teología de la liberación. Revista Espiga, 16(33), 61-76. https://doi.org/10.22458/re.v16i33.1764

Fernández Eyzaguirre, S. (2013). Arrio y la configuración inicial de la controversia arriana. Scripta Theologica, 45(1), 9-40. Recuperado de https://ixtheo.de/Record/1640857931

Ferrara, R. (2005). El misterio de Dios: correspondencias y paradojas. Salamanca: Sígueme.

Feuerbach, L. (1956). Das Wesen des Christentums: Vollstëndige Ausgabe. Berlín: Akademie Verlag.

Francisco. Vaticano II. Vangelii gaudium. Nov 4 de 2013. Recuperado de http://www.vatican.va/content/francesco/ es/apost_exhortations/documents/papa-francesco_esortazione-ap_20131124_evangelii-gaudium.html

Francisco. Vaticano II. I Jornada Mundial de los Pobres Domingo. Nov 19 de 2017. Recuperado de http://www. vatican.va/content/francesco/es/messages/poveri/documents/papa-francesco_20170613_messaggio-igiornatamondiale-poveri-2017.html

Francisco. Vaticano II. 51 Jornada Mundial de la Paz. En 1 de 2018. http://www.vatican.va/content/francesco/ es/messages/peace/documents/papa-francesco_20171113_messaggio-51giornatamondiale-pace2018.html 
Francisco. Vaticano II. Fratelli tutti. Oct 3 de 2020. http://www.vatican.va/content/francesco/es/encyclicals/ documents/papa-francesco_20201003_enciclica-fratelli-tutti.html

Greshake, G. (2001). El Dios uno y trino: una teología de la Trinidad. Barcelona: Herder.

Heidegger, M. (1988). Identidad y diferencia. Anthropos Editorial.

Kasper, W. (2013). El Dios de Jesucristo. Santander: Sal Terrae.

Kusch, R. (2000). Obras completas (t. 1). Rosario: Fundación Ross.

Marion, J. L. (2010). Dios sin el ser. Pontevedra: Ellago.

Meyendorff, J. (1989), The role of Christ, I: Christ as saviour in the east. Christian Spirituality, 1, 231-252.

Moore, M. (2020). De dioses y pandemias. En Covid-19: Sociedad Argentina de Teología (pp. 78-84). Buenos Aires: Sociedad Argentina de Teología.

Müller, G. L. y Gutiérrez, G. (2005). Del lado de los pobres: teología de la liberación. Lima: Instituto Bartolomé de las Casas.

Noemi, J. (2007). En la búsqueda de una teología de los "signos de los tiempos". Teología y Vida, 48(4), 439-447. http://dx.doi.org/10.4067/S0049-34492007000300007

Retamozo, M. (2007). Enrique Dussel: hacia una filosofía política de la liberación. Notas en torno a 20 tesis de política. Utopia y Praxis Latinoamericana, 12(36), 107-123. http://ve.scielo.org/scielo.php?script=sci_arttex t\&pid=S1315-52162007000100007

Ricoeur, P. (1976). De la interpretación a la traducción. En Exégesis y hermenéutica (pp. 337-365). Madrid: Cristiandad.

Sobrino, J. (2007). El Jesús histórico nos llama al discipulado en América Latina y el Caribe. Theologica Xaveriana, 57(161), 127-157. https://www.redalyc.org/pdf/1910/191017410007.pdf

Tomichá Charupá, R. (2019). Diez consideraciones para una pneumatología cristiana en perspectiva indígena. Teología, 56(129), 117-151. https://erevistas.uca.edu.ar/index.php/TEO/article/view/2414/2238 